\title{
An Analysis of Causes for Loss of Cultural Rights of Migrant Workers
}

\author{
Qiang Zhang ${ }^{1}$ \\ ${ }^{1}$ College of Politics, Sichuan Agricultural University, Ya'an, China \\ Correspondence: Qiang Zhang, College of Politics, Sichuan Agricultural University, Ya'an 625014, China. \\ E-mail: zqwxyhn@163.com
}

Received: July 2, 2012 Accepted: July 24, 2012 Online Published: October 19, 2012

doi:10.5539/ass.v8n13p188 URL: http://dx.doi.org/10.5539/ass.v8n13p188

Supported by the "shuangzhi Plan" of Sichuan Agricultural University (00870704)

\begin{abstract}
The fact that migrant workers are a vulnerable group not only means that their economic interests are unlikely to be effectively guaranteed, but also means general loss of their cultural rights. This paper makes an analysis of causes for loss of cultural rights of migrant workers mainly from three aspects, namely, insufficient awareness and ineffective security of the government, inadequate social concern and no strong atmosphere and vulnerability and weak aspiration of migrant workers. Namely, the author makes a macro analysis from the three aspects of the government, the society and migrant workers. Only if we analyze both the subjective and objective causes for loss of cultural rights of migrant workers in a correct way, is it likely to find out a proper policy to resolve loss of cultural rights of migrant workers.
\end{abstract}

Keywords: migrant workers, cultural rights, loss

In the past few years, construction of public cultural service system in China has been boosted in its proper order and basic cultural rights of migrant workers have gradually got guaranteed. However, generally speaking, satisfaction of basic cultural demand by migrant workers is low and the cultural life of migrant workers is tedious and deficient, which lead to a lot of issues. For example, migrant workers are at a transition from "farmers" to "townspeople", so their self-identity is ambiguous, their work and life space is relatively isolated from urban residents, their cultural habit has great difference from that of urban residents, their communicative objects are limited, they have no sense of belongs to the city where they reside and they are lacking in effective communication and integration with urban residents in terms of culture. Especially, the new generation of migrant workers is at a golden period of making friends, love and marriage, their demand on thought exchange and emotional communication is strong and the level of their demand on culture is constantly enhanced, as a result of which they generally feel emotional solitude and even psychological issues occur to some of them, bringing hidden dangers to stability of the society. Only if we analyze both the subjective and objective causes for loss of cultural rights of migrant workers in a correct way, is it likely to find out a proper policy to resolve loss of cultural rights of migrant workers.

At present, there are various causes that affect the normal cultural life of migrant workers, which can be summarized as the following several aspects.

\section{Insufficient Awareness and Ineffective Security of the Government}

\subsection{Insufficient Awareness and Inadequate Attention}

Cultural life of migrant workers does not only have the urban characteristics, but more have rural features. Hence, only if we go deep to conduct a social and cultural survey on migrant workers, make a profound analysis of the characteristics of cultural demand of migrant workers, grasp their consumption habits, summarize their consumption rule and take an initiative in exploring artistic patterns that are suitable for cultural life of migrant workers, can we provide migrant workers with healthy and beneficial cultural products and service. However, as a matter of fact, the government at all levels has the following problems in terms of conducting cultural work for migrant workers: insufficient emphasis, laggard systematic study and insufficient pertinence and efficiency of the work. Some local governments tend to have insufficient awareness of the significance of ensuring spiritual and cultural rights of migrant workers. Instead, they only see migrant workers nothing more than simple labor 
forces who are on call at any hour and they are merely aware of their demands on the material life, but ignore their demand on spiritual and cultural life. When they resolve problems related with migrant workers, they only pay attention to resolving their economic interests, such as, salary and welfare, but ignore their spiritual and cultural rights. At the same time, out of consideration of finance and resources, the government of the local area which migrant workers flow into are unwilling to shoulder these seemingly extra burdens of education, spiritual and cultural life and cultural facilities of migrant workers. Thus, they choose to show indifference to the spiritual and cultural life of migrant workers. Although some areas and departments do have made efforts and have taken some measures, the strength and width is far from enough, lacking in initiative of cultural consideration and corresponding public resources allocation. In one word, the cultural facilities and programs that the government has so far provided for migrant workers are far from satisfying the demand of migrant workers and migrant workers are at a state of serious cultural hunger and thirst.

\subsection{Unsmooth System and Ineffective Security}

As a vulnerable group, migrant workers' cultural rights have been ignored for quite a long time and are either not indispensable or run their own course. The primary cause is that the country and the society have not set up a service system special for cultural rights of migrant workers. For the time being, the government still gives priority consideration to urban residents in designing a public cultural service system, while such measures are in deficiency as to aim at public cultural service system of migrant workers and to guarantee their cultural rights. This leads to shortage of public cultural consumer goods that can be afforded by migrant workers and as a result, migrant workers are unable to really share a variety of cultural services offered in the urban cities. It is reported, a construction company in Beijing has signed contract of services with tens of thousands of migrant workers in succession, but the labor and social security department has never requested to provide cultural facilities or cultural entertainment activities for these migrant workers. Therefore, Labor and Social Security Department in Haidian District of Beijing holds such a view, "What the labor department is obliged to do is to punish any illegal employment and any behavior infringing upon the rights of employees in pursuant to the Labor Law. As to the spare-time life and spiritual life of migrant workers, it is the private life of migrant workers and do not fall within the scope of legal regulation. Therefore, the administrative enforcement department can't and also should not interfere." It is also believed by the Trade Union, "The major function of the trade union is to assist migrant workers to maintain their legal rights. That is, when the rights of migrant workers are encroached, the trade union has the obligation to stand out to speak for the migrant workers. As to the spare-time cultural life of migrant workers, it is really difficult for the trade union to have any action." The lawyer in Beijing Tianyuan Law Firm and also a legal practitioner, explicitly affirms, "There is no specific prescription in the laws and regulations as to how to enrich the spare-time cultural life of migrant workers." Thus, it can be seen, it is exactly because there is no relevant express provision and there is no security of institutional service system, the employment unit, the trade union and the labor and social security department all hold the viewpoint that there is no relevant provision about the cultural life of migrant workers, let alone any system requesting for implementation of such a provision. Without any law or evidence, the cultural life of migrant workers is at an insignificant state of "coming within nobody's jurisdiction." This not seriously affects the physiological health of migrant workers and the social harmony, but also is quite unfavorable for long term and stable development of the entire society.

\section{Inadequate Social Concern and No Strong Atmosphere}

\subsection{Ignorance of the Employment Units}

Employment units are the major occasion for migrant workers' work and life. According to the statistical data, approximately $51.8 \%$ of migrant workers live in the dormitories furnished by employment units. It can be seen that employment units are of great importance to construction of cultural rights of migrant workers. However, in point of fact, out of consideration to reduce the costs, the employment units are reluctant to make a long term plan for cultural life and cultural facilities of migrant workers. Since spiritual and cultural life is unlikely to bring direct economic benefits and still further investment of funds is required, a large majority of enterprises fail to show concern for demand of employees on spiritual and cultural life. In addition, these enterprises also fail to regard it one of the rights of migrant workers to share spiritual and cultural life. In the eyes of these enterprises, it is not their obligation to enrich the life of migrant workers. Jing Houyin, the journalist of "Economic Daily" investigated several construction companies and construction sites in Beijing and construction sites of all companies had not offered any cultural facility. "Migrant workers provide labor and we pay them salary. The spare-time life of migrant workers is none of our business as neither this is prescribed in the contract nor there is such a tradition in the construction industry." The manager of a certain construction company also said so when he was interviewed. Besides, he also said, it might not expense too much to build a simple book room and place 
two table tennis tables on the construction site. However, "This is not prescribed in the contract and there is no such tradition in the construction industry, so both the construction party and the building party do not see it as an obligation." (Liu Lijuan \& Li Xiaodong, 2011, May)

\subsection{Indifference of Urban Community}

A small number of migrant workers work and live in the employment units, while a large majority of migrant workers reside in a variety of communities in the cities either by means of shared accommodation or independent rent or self-purchasing of a residential place. The various urban communities are the primary gather place for migrant workers. Nonetheless, when the urban communities plan the community facilities and services, they usually consider the permanent resident population within the communities as the major object, and fail to take into consideration of the cultural demand of migrant workers who reside within the area under administration of the communities. As a result, it is unlikely to ensure that migrant workers have equal opportunities and rights to share community cultural facilities as the community residents. In the public affairs and public benefit activities of the community, relevant departments usually show indifference for appeal of migrant workers, let alone allowing migrant workers to participate in administration of social and community affairs. As a result, they are also absent from any social participation. It is disclosed in the survey that, almost $76.7 \%$ of migrant workers who enter the urban areas to seek for a job have never taken part in cultural activities organized by the community (including street committee and neighborhood committee, etc.), 10.3\% of migrant workers have the right to take part in these activities once half a year, $10.0 \%$ of migrant workers have the opportunity to take part in these activities once a year and $3.0 \%$ of them can take part in these activities once more than two years. As a result of low participation rate, the migrant workers have no way to share the responsibility for the development of the community, let alone sharing the development achievements of the community. In a survey on causes why migrant workers never or seldom take part in activities organized by the community, $38.3 \%$ of migrant workers answer that, "they have never heard about any activity", $34 \%$ of migrant workers answer "there is no one who organizes migrant workers from the rural areas to participate in such activities". These two options add up to exceed $70 \%$. (Ma Chunhong, 2007, July) This indicates that the urban government and relevant administrative department ought to alter their concept, carry out positive administrative policy for migrant workers, bring migrant workers into activities of the community, enable them to become the subject of community participation and enable them to be really brought to the urban social system in the social life. This helps to foster the sense of responsibility and sense of belongs of migrant workers towards the community and maintain the political and social rights of migrant workers.

\section{Vulnerability and Weak Aspiration of Migrant Workers}

\subsection{Low and Unstable Income Makes Migrant Workers Unaffordable for Cultural Consumption}

The major reason for migrant workers to migrant to urban cities to seek for a job is consideration of economic benefit. However, a large majority of migrant workers are employed for positions with low income level, bad working environment, low salary and low welfare, which, without doubt, constrain their income level. For migrant workers, to a large extent, their consumption capacity of leisure cultural life depends upon their salary. The lower their salary is, the expense they use for leisure cultural life is lower. However, in the current institutional environment, the actual income of migrant workers is temporary and they have no strong confidence in long-lasting income." (Ma Chunhong, 2007). This urges them to deposit a large part of their low temporary income for expense in the future instead of current consumption, especially cultural consumption. It is revealed by the survey that, there are seldom migrant workers who do not begrudge to use their money for cultural consumption. In addition to necessary living expense, their income is rarely used for other consumption, such as, cultural consumption. Most of them insist on the living principle of "save as possible as one can". (Liu Qiying, 2010, April). At the same time, as a result of the traditional dual urban and rural economic structure and system, migrant workers are unlikely to acquire an identity as an urban resident. The household registration system determines their particular social identity and social status. That is to say, they neither belong to urban residents, nor have the same identity with traditional farmers. This kind of marginal identity makes it difficult for migrant workers to get the social security, such as, medical insurance, endowment insurance and unemployment insurance and leads to greater uncertainty of their life than any other group. This also causes them to have the consciousness of strongly worrying about the future, as a result of which they deposit all their savings instead of using them for consumption. Hence, the temporary and low income and lack of social security become a fundamental cause that constrains cultural life of migrant workers. 


\subsection{Low Educational Background Becomes an Obstacle of Migrant Workers in Sharing High Quality Cultural} life in the Urban Cities

Educational background of an individual migrant worker will affect his selection of cultural life mode. Both consumption cultural life mode and creative cultural life mode, to a certain extent, need to resort to the surrounding cultural information and cultural quality of the migrant worker. And education endows, to a certain extent, people with the skills to use the surrounding cultural knowledge and the ability to enhance their cultural quality. However, the entire educational background of migrant workers is relatively low, and most of them graduate from middle schools, and there are even some migrant workers who graduate from the primary school. This causes the migrant workers to often encounter a lot of difficulties in their participation in urban cultural entertainment activities, especially cultural activities with high quality. For instance, reading, surfing the internet, technical training and visiting a cultural exhibition and artistic activity all need certain cultural knowledge and cultural deposits, which, without doubt, is quite difficult for the migrant workers who have low cultural level to overcome. Therefore, they have no other choice but to choose those entertainment activities which hardly need any knowledge or skill and which have low cultural connotation. For example, they may choose to have a chat, play cards and watch TV, etc. This is also one of the causes that lead to tediousness, baldness and tastelessness of cultural life of migrant workers.

\section{Concluding Remark}

The above three sections have respectively analyzed causes for loss of cultural rights of migrant workers from the three aspects of the government, the society and migrant workers themselves. Thus, it can be seen, improvement of cultural ecology of migrant workers is a systematic social project. This clamors for relevant departments to integrate strengths from all aspects, take measures, practically improve the cultural life of this vulnerable group of migrant workers in urban areas, give full play to cultural work in enhancing the ideological and moral quality and scientific and cultural quality of migrant workers, enable migrant workers to continuously strengthen their cultural construction in the process of urban construction and provide powerful spiritual motive power, intellectual support and ideological security for urban and rural economic and social development.

\section{References}

Liu, L. J., \& Li, X. D. (2011, May). Responsibility of the Government for Security of Cultural Rights of Migrant Workers. Journal of Changchun University of Technology (Social Sciences Edition).

Liu, Q. Y. (2010, April). Cultural Rights of Migrant Workers: An Analysis of Dilemma and Security Mechanism. Theory and Reform.

Ma, C. H. (2007). Study on Leisure Life of Migrant Workers and Urban Community Construction. Xiangtan University Press.

Ma, C. H. (2007, July). Roaming on the Margin of City--Survey on Peasant Worker's Leisure Life in Changsha. Journal of Xiangtan University (Philosophy and Social Sciences). 